\title{
The endocrine role of the skeleton: background and clinical evidence
}

\author{
Verena Schwetz, Thomas Pieber and Barbara Obermayer-Pietsch \\ Division of Endocrinology and Metabolism, Department of Internal Medicine, Medical University of Graz, Auenbruggerplatz 15, A 8036 Graz, Austria \\ (Correspondence should be addressed to B Obermayer-Pietsch; Email: barbara.obermayer@medunigraz.at)
}

\begin{abstract}
Based on the observation that diabetes, obesity, and hypogonadism influence bone metabolism, the existence of a feedback loop and a common regulation was postulated and an endocrine role ascribed to the skeleton. In the first part of this review, two pathways are described whereby adipose tissue acts on bone mass. In the first, leptin activates the sympathetic nervous system via serotonin and diminishes bone mass accrual. The second pathway functions via the activation of CART (CARTPT) and inhibits bone resorption. The first pathway leads to a decrease in bioactivity of the osteoblast-produced hormone osteocalcin (OC) (part 2). In its undercarboxylated form, OC acts on the three targets pancreas, adipose tissue, and gonads (part 3) and thereby causes an increase in insulin secretion and sensitivity, $\beta$-cell proliferation, and male fertility. Insulin (part 4) is part of a recently discovered regulatory feedback loop between pancreas and osteoblasts. It is a strong counterplayer of leptin as it causes a decrease in OPG expression and enhances bone resorption and OC decarboxylation. Numerous clinical studies (part 5) have shown associations of total and undercarboxylated OC and markers of energy metabolism. Interventional studies, to date only performed in murine models, have shown positive effects of OC administration on energy metabolism. Whether bone tissue has an even further-reaching endocrine role remains to be elucidated.
\end{abstract}

European Journal of Endocrinology 166 959-967

\section{Introduction}

For a long time, only classical actions have been attributed to the skeleton such as the protection and stabilization of the body and support in locomotion. In addition, bone is considered a site for hematopoiesis and serves as a pivotal organ in calcium and phosphorus homeostasis. Recently, however, a further-reaching, endocrine role affecting the entire organism has been suggested for the skeleton.

A first hypothesis, developed by Karsenty et al. (1, 2), postulated the regulation of bone remodeling by energy metabolism, derived from clinical observations such as a less frequent occurrence of osteoporosis in obesity and increased cases of osteoporosis in hypogonadal patients (3). These findings suggested a connection as well as a common regulation of bone, energy metabolism, and reproduction. Bone per se could be involved in the regulation of glucose metabolism and reproduction provided the skeleton is truly an endocrine organ (3).

This review describes how adipose tissue acts on bone mass via two distinct pathways, why bone tissue can be considered an endocrine organ, and the effects it has on its three main targets. The regulatory feedback loop between pancreas, osteoblasts, and bone resorption is described and the results from clinical studies are depicted.

\section{Adipose tissue acts on bone mass via two indirect pathways}

As appetite and reproduction are regulated by the hypothalamus, it is assumed that bone metabolism might likewise be subject to hypothalamic control. These assumptions drew the attention toward leptin (1), which is produced by adipocytes and functions in the brain. Leptin is held responsible for the inhibition of appetite and the favoring of reproductive function, as documented by obese and sterile leptin-deficient $o b / o b$ and leptin receptor-deficient $d b / d b$ mice (2). The regulation of bone metabolism is also a function of leptin, as it acts on osteoblasts via two different neural pathways $(1,2)$ (Fig. 1) as seen in $o b / o b$ and $d b / d b$ mice. The absence of leptin had caused hypogonadism and elevated glucocorticoid levels. Nonetheless, these mice showed an increase in bone formation as a result of the 
Leptin $\rightarrow$ serotonin $\downarrow \rightarrow$ SNS $\uparrow \rightarrow$ osteoblast proliferation $\downarrow$ and RANKL $\uparrow \rightarrow$ bone resorption $\uparrow$ (64) Leptin $\rightarrow$ CART $\uparrow \rightarrow$ RANKL $\downarrow(18)$

Leptin $\rightarrow$ serotonin $\downarrow \rightarrow \mathrm{SNS} \uparrow \rightarrow E S P \uparrow \rightarrow$ decarboxylation of OC $\downarrow \rightarrow$ OC bioactivity $\downarrow$ (8)

Leptin $\rightarrow$ direct influence on $\beta$-cells $\rightarrow$ insulin secretion $\downarrow(28,14)$

Figure 1 Bone-related functions of leptin. The figures in parentheses represent references $(8,14,18,28,64)$.

absence of leptin. In these experiments, leptin or PBS was infused into the third ventricle of $o b / o b$ mice to observe whether leptin could correct this high bone phenotype via a central mechanism. Leptin-treated but not PBS-treated mice fully recovered their bone phenotype. By infusion into wild-type mice, leptin was shown to lower bone mass even under physiological conditions (1). This experiment supports the idea of a central and catabolic regulation of bone metabolism by leptin $(1,2)$. In a study using Cre/LoxP transgenic mice, the leptin receptor was deleted in neurons and osteoblasts (4). Neuronal deletion resulted in an increase in bone formation and bone resorption, leading to a high bone mass (4). The same deletion in osteoblasts did not have an effect on bone remodeling (4). In a mouse model with a partial gain of function of leptin signaling ( $1 / 1$ mice), Shi et al. (4) could show that leptin signaling inhibits bone mass accrual via the sympathetic nervous system (SNS). $1 / 1$ mice thus had a low bone mass phenotype, especially at the trabecular bone $(4,5)$, even though appetite, energy expenditure, and reproductive function were normal (4). The fact that only bone mass accrual was affected, but not appetite and reproduction, implies that the threshold of leptin signaling needed to affect bone mass might be lower (6).

Beyond physiological studies performed with transgenic mice, several pharmacological studies using much higher doses of leptin revealed a peripheral and anabolic action of leptin on bone mass. Leptin has been shown to enhance proliferation of isolated fetal rat osteoblasts, which expressed the signaling form of the leptin receptor (7). In vivo, systemic injection of leptin into adult male mice reduced bone fragility (7). Additionally, an inhibition of osteoclast formation by leptin has been demonstrated (8). Bartell et al. (9) compared the impact of i.c.v. or s.c. administration of leptin on bone in $o b / o b$ mice. Regardless of mode of administration, leptin increased bone mineral density, bone mineral content, bone area, and mineral apposition rate (9). Williams et al. (10) compared the bone phenotype of $d b / d b$ and wild-type mice using microcomputed tomographic analysis. $\mathrm{Db} / \mathrm{d} b$ mice had significantly lower cortical and trabecular bone volume and thickness and a lower trabecular number in the tibias as well as a lower cortical and trabecular bone thickness in the vertebrae (10). These studies suggest an anabolic rather than a catabolic function as well as a central and peripheral mechanism of action of leptin with regard to bone metabolism.
But what are the mechanisms of the proposed central regulation of bone metabolism by leptin?

Independent of these findings and considerations, it has been shown that selective serotonin reuptake inhibitors (SSRI) in humans are associated with increased appetite, odds of falling, lower BMD at the hip, and a trend toward lower BMD at the spine (11). In a meta-analysis of 13 studies conducted by $\mathrm{Wu}$ et al. (12), the use of SSRIs has been associated with an elevated rate of fractures. This association was also seen in studies that had adjusted for bone mineral density and depression (12). These findings suggest a connection or a common pathway of serotonin and leptin.

Experiments have shown that in order to inhibit appetite and bone mass accrual, leptin depends on the integrity of hypothalamic neurons but not on the expression of its hypothalamic receptor ObRb on these neurons (13), proposing the existence of an intermediary neurotransmitter. Indeed, not all its actions are exerted by binding to hypothalamic receptors. Instead, leptin acts in the brainstem to inhibit the synthesis and release of serotonin from the raphe nuclei (6) (Fig. 2). Brain-derived serotonin binds to HTR2C receptors of VMH neurons in the hypothalamus, decreases signaling of the SNS, and thus increases bone mass accrual $(13,14)$. By binding to HTR1A and HTR2B receptors in the arcuate nuclei of the hypothalamus, serotonin increases appetite (13). Serotonin is thus an important mediator in regulating bone mass and appetite. Leptin, by decreasing serotonin synthesis, increases signaling by the SNS, which exerts its function via $\beta 2$ adrenergic receptors expressed on osteoblasts. Thereby it activates two distinct cascades (15). The first one inhibits osteoblast proliferation and the other one promotes RANKL (TNFSF 11) expression and thus bone resorption (2).

When leptin binds to receptors on the neurons of the arcuate nuclei, however, it induces an increase in the expression of a gene called CART (cocaine- and amphetamine-regulated transcript; CARTPT) $(16,17)$. CART decreases RANKL expression by osteoblasts via a yet unknown mechanism and thus inhibits bone resorption - the second pathway of leptin regulation (Fig. 2 upper part) (18). It is assumed that CART acts more as a circulating factor than a neuropeptide, as an increase in the circulating levels of CART can rescue the low bone mass phenotype of $\mathrm{Cart}^{-/-}$mice (19). In wildtype mice, a decrease in bone resorption could be induced (19). Whether CART affects gene expression in osteoblasts via a direct of indirect mechanism remains currently unknown (19). All in all, leptin prevents bone mass accrual through the combined action of the SNS and CART (2).

The value of a common hormonal regulation of bone metabolism and appetite might have evolutionary reasons. As bone remodeling, important for the repair of micro- and macro-damages in the skeleton, and thus essential for mobility, is costly in terms of energy expenditure, it strongly relies on a constant supply (13). 


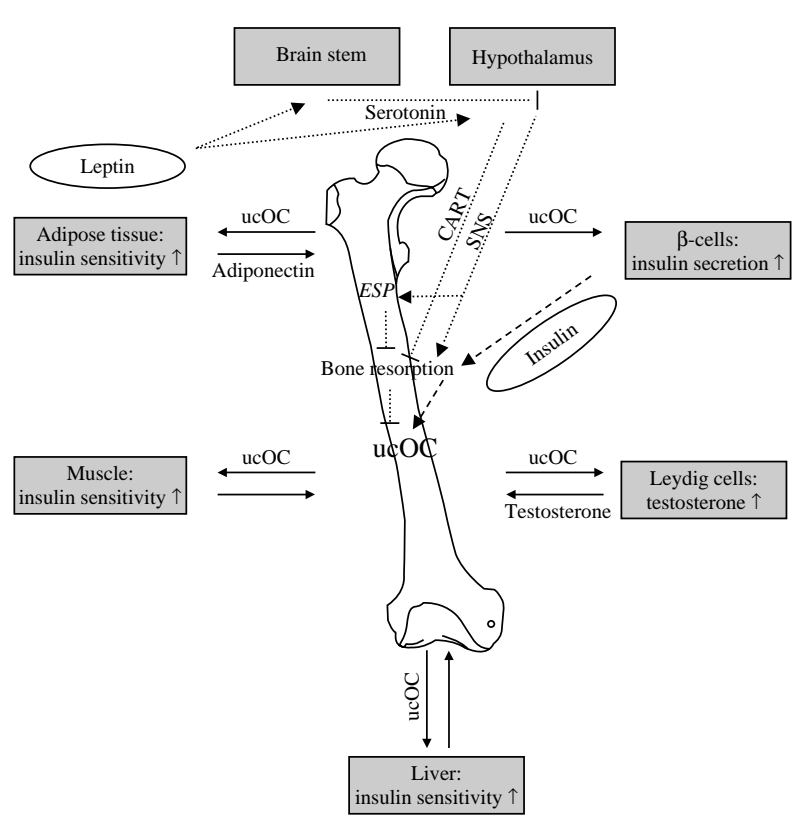

Figure 2 Bone as an endocrine organ and its influences on the whole body. COC, carboxylated OC; SNS, sympathetic nervous system; uCOC, undercarboxylated OC. Upper part: adipocyteproduced leptin inhibits the production of serotonin in the brain. Serotonin reduces the activity of the sympathetic nervous system. Leptin signaling thus increases the sympathetic tone and consequently bone resorption. Leptin binds to neurons of the arcuate nuclei and increases the expression of cocaine- and amphetamineregulated transcript (Cart) whereby bone resorption is decreased. All in all, through CART and the SNS, leptin prevents bone mass accrual. Lower part: OC bioactivity is controlled by two counteracting hormones - leptin and insulin. In addition to enhancing bone resorption via the two above-described pathways, leptin increases the expression of ESP and thus reduces OC bioactivity as the intracellular protein tyrosine phosphatase, OST-PTP, encoded by $E S P$, favors OC carboxylation. Insulin signaling in osteoblasts, on the contrary, causes a decrease in osteoprotegerin (OPG) expression and the OPG/RANKL ratio and thus enhances bone resorption. $\mathrm{OC}$ decarboxylation is stimulated. The functions of ucOC include the increase in insulin secretion in $\beta$-cells and the increase in insulin sensitivity in muscle, liver, and adipose tissue, as well as an increase in testosterone production in Leydig cells.

\section{Bone acts as an endocrine organ}

The protein osteocalcin (OC), also referred to as bone GLA protein, is produced by osteoblasts and odontoblasts and has been known as a marker of bone turnover $(20,21)$. It is carboxylated posttranslationally on three glutamic acid residues in a vitamin K-dependent manner by the enzyme $\gamma$-glutamyl carboxylase. The resulting amino acid $\gamma$-carboxyglutamic acid (Gla) has the property to bind to free calcium and calciumcontaining mineral surfaces $(22,23)$. OC contains three Gla residues that provide high affinity for bone matrix. OC is the predominant GLA protein in bone (23). Decarboxylation diminishes the hydroxyapatite-binding affinity of OC. Undercarboxylated OC (ucOC) is a measure for the status of vitamin $\mathrm{K}$ in bone as vitamin $\mathrm{K}$ depletion increases and vitamin $\mathrm{K}$ supplementation decreases levels of ucOC (24). Both the fully carboxylated OC $(\mathrm{COC})$, considered biologically inactive, and ucOC, regarded biologically active, are distributed in the systemic circulation (25). Undercarboxylated forms of OC show hormonal characteristics such as the cell specificity of its gene, release in a circadian pattern, and synthesis as a pre-pro-molecule (23). ucOC might play a major role in the regulation of the energy metabolism, such as the increase in $\beta$-cell proliferation, insulin secretion and sensitivity, and energy consumption (25). Bone tissue thus seems to have a direct effect on energy metabolism.

The first evidence was provided by Lee et al. in 2007 (25) with the identification of a gene called ESP (PTPRVP). It encodes for the intracellular protein tyrosine phosphatase OST-PTP, or protein tyrosine phosphatase 1B (PTP1B (PTPN1)) as the counterpart in humans, and thus favors carboxylation of OC. So, PTP1B and $\gamma$-carboxylase are osteoblast-derived regulators of OC bioactivity.

By deleting the only adrenergic receptor expressed in osteoblasts in mice, the $\beta 2$ adrenergic receptor, Hinoi et al. (26) were able to show that leptin signaling via the sympathetic tone regulates insulin secretion through the cascades in osteoblasts. These mice demonstrated increased serum insulin and low postprandial serum glucose levels. Expressions in insulin, glucokinase, and cyclin-dependent kinase 4 (CDK4) were elevated. More precisely, leptin increased the expression of ESP in osteoblasts, which diminished bioactivity of $\mathrm{OC}$ and hampered its metabolic function $(25,26,27)$. Thereby, insulin secretion was decreased (26). Additionally, leptin acted directly on $\beta$-cells to block the secretion of insulin $(28,29)$. Of note, by enhancing bone resorption, the active, undercarboxylated form of $\mathrm{OC}$ is indirectly released (Fig. 2).

\section{OC has three known targets: pancreas, gonads, and adipose tissue}

The importance of this newly identified hormone for the human body was hinted in experiments using $\mathrm{OC}^{-1-}$ mice, which exhibited a decrease in insulin secretion and sensitivity, diminished $\beta$-cell proliferation, decreased energy expenditure, and increased fat mass. As a result, $O C^{-1-}$ mice were more likely to be insulin resistant or glucose intolerant (25) and showed an early development of obesity while possessing a normal bone phenotype, even under a normal diet (3). Compared with $O C^{-1-}$ mice, $E s p^{-1-}$ mice had significantly higher levels of serum ucOC and showed the opposite metabolic phenotype (25). At birth, they displayed severe hypoglycemia. In adult mice, glucose levels were also abnormally low. In addition, Esp ${ }^{-1-}$ mice showed elevated C-peptide levels and hyperinsulinemia. 
Glucagon levels were normal, as they were suppressed by insulin. Glucose tolerance was higher, and despite hyperinsulinemia, insulin sensitivity was also increased compared with WT mice. The number of islets, islet size, $\beta$-cell mass, and pancreatic insulin content were elevated in $E s p^{-1-}$ mice. Gonadal fat pads, liver fat content, body weight, and triglyceride levels were lower. Energy expenditure and serum adiponectin levels, contributing to insulin sensitivity, were higher. In addition, they presented with increased bone resorption (30) caused by a decrease in OPG secretion. Introducing one allele of the OC mutation into $\mathrm{Esp}^{-1-}$ mice or treating them with an antiresorptive drug normalized their metabolic phenotype (30).

In adipose tissue, $O C$ increases expression of the gene $A D I P O Q$ encoding adiponectin, which enhances insulin sensitivity $(25,27)$. By the presence of adiponectin receptors on osteoblasts, adiponectin can induce proliferation and differentiation of the same (31).

Recent findings have revealed yet another target of OC beyond the pancreas and the insulin-sensitive tissue muscle, liver, and fat: the gonads. OC seems to induce testosterone production in Leydig cells but lacks an influence on estrogen or testosterone production in the ovaries (32). This is due to the newly identified ucOC G protein-coupled receptor (GPRC6A) expressed in testes but not in ovaries (33). By binding to GPRC6A, ucOC promotes fertility as increased testosterone production has positive effects in reducing germ cell apoptosis (33).

Foresta et al. (34) have recently suggested a role of adipocytes in the secretion of $\mathrm{OC}-$ until then perceived as the product of mature osteoblasts only - which expands the model proposed by Gerard Karsenty. In gene expression and immunohistochemistry analyses, it could be demonstrated that visceral and subcutaneous adipose tissue express $O C$ mRNA and all genes involved in carboxylation $(\gamma$-glutamyl carboxylase, GGCX, and both isoforms of vitamin K-epoxide reductase complex, subunit 1, VKORC1 isoforms 1 and 2) (34). In vitro, adipose tissue released OC in its undercarboxylated and carboxylated form. In a subsequent study, it was demonstrated that androgens acting on adipose tissue increase the expression of both forms of OC. Various studies have shown that androgens are lowered in obese men $(35,36,37,38)$. Decreased androgen levels in patients with metabolic disturbances might therefore in part explain low OC levels in the same patients. More studies are warranted to investigate the contribution of osteoblast- and adipocyte-derived OC to energy metabolism.

\section{The regulatory feedback loop between pancreas, osteoblasts, and bone resorption}

With the discovery of the feedback loop between pancreas and osteoblasts, a major counterplayer of leptin was revealed: insulin, a positive regulator of $\mathrm{OC}$ bioactivity (Fig. 2 lower part).

The insulin receptor is a tyrosine kinase and is expressed on osteoblasts. It is as such a substrate of the tyrosine phosphatase OST-PTP encoded by ESP. Consequently, the insulin signaling cascade can be interrupted by OST-PTP. If this is not the case, the binding of insulin to its receptor causes a decrease in osteoprotegerin (OPG (TNFRSF11B)) expression and of OPG/RANKL ratio in a FOXO1-dependent manner. Bone resorption is enhanced and the extracellular matrix in the bone acidified (30). The change in $\mathrm{pH}$ enables the release of $\mathrm{OC}$ from the bone matrix and its subsequent decarboxylation. ucOC is released into the systemic circulation, where the carboxylated form can also be found and exerts its positive effects on insulinsensitive tissues. The status of decarboxylation is in fact determined by the osteoclasts as the acidic milieu in the resorption lacunae is responsible for decarboxylation. These findings support the central role of insulin signaling in osteoblasts and denote bone resorption as the key link between bone remodeling and energy metabolism (30).

\section{OC and metabolism: clinical evidence}

\section{Total OC and markers of metabolic phenotype}

A study by Rosato et al. from 1998, comparing diabetic patients with healthy subjects, is one of the earliest reports showing an association between glucose metabolism and OC in a clinical setting. Baseline levels of serum OC were significantly lower in diabetic patients. An improvement in glycemic control raised serum levels of insulin-like growth factor 1 (IGF1) and OC significantly (39). Clinical studies such as the MrOS Sweden Study (osteoporotic fractures in men) (40) showed that Swedish male diabetics likewise had significantly lower plasma OC levels than nondiabetic Swedish men. In addition, Kindblom et al. (40) and Pittas et al. (41) were able to show for the first time a significant inverse correlation between plasma OC and BMI, fat mass, and plasma glucose.

Inverse correlations between plasma total $\mathrm{OC}$ and fasting insulin (41), insulin resistance $(41,42,43)$, and systemic inflammation (CRP, IL6) (41) have been shown. Upon glucose load, total OC decreased from baseline to $120 \mathrm{~min}$ (44).

A study by Levinger et al. (45) has reported increases in $\mathrm{ucOC}$ in obese men and diabetics upon aerobic training, which might be in part responsible for the decrease in glucose levels during the workout. Men performing power training demonstrated a comparable decrease in glucose levels; ucOC levels, however, only marginally increased, suggesting new, yet unknown factors involved. Similar studies could not detect 
any increase in total OC levels after training $(46,47$, $48,49)$.

In obese children after substantial weight loss, OC levels increased and leptin and insulin resistance (expressed by homeostatic model assessment-insulin resistance index, HOMA-IR) decreased significantly (50). Fernandez-Real et al. (42) also detected increases in OC accompanying reductions in visceral fat mass in their adult patients after weight loss and increases in regular exercise. After bariatric surgery, regardless of the procedure applied, total OC levels increased during the first 12-24 months but started decreasing after that time period (51). Adiposity measures were found to correlate inversely with OC (52).

Interestingly, OC levels were higher in pregnant women with gestational diabetes compared with pregnant women with normal glucose tolerance. Twelve weeks after giving birth, OC levels equaled between the two groups. These findings suggest a compensatory increase in $\mathrm{OC}$ in the presence of impaired glucose tolerance during pregnancy (53).

Further clinical studies showed similar associations between $\mathrm{OC}$ and metabolic parameters such as a negative correlation with $\mathrm{HbAlc}(54,55)$ and a positive correlation with adiponectin $(54,56)$. Patients with nonalcoholic fatty liver disease had lower levels of total serum OC than healthy controls; OC was inversely associated with ALT, AST, HOMA-IR, and hepatocyte ballooning in these patients.

By contrast, low as well as high levels (first and fifth quintile respectively) of total OC have been associated with all-cause and cardiovascular mortality in a study of 3542 older men (57). Whether this can be attributed to the altered bone turnover or to the biological activity of OC remains unclear (57).

\section{oc, leptin, and adiponectin}

A study by Gravenstein et al. (58) provides clinical evidence for the findings that glucose metabolism is regulated by OC in a leptin-dependent way. Leptin is strongly positively associated with insulin resistance and secretion, and both adiponectin and OC show a negative association with insulin resistance. However, Schafer et al. (59) could not find an association of ucOC with leptin.

In accordance with the data from cell culture experiments, where it has been shown that ucOC increases adiponectin expression from adipocytes (25, 27), higher ucOC levels have been associated with higher adiponectin levels in a clinical setting (59). In addition, a decrease in fat mass is accompanied by an increase in adiponectin levels $(60,61)$.

\section{Clinical evidence from measurement of ucOC}

Most of the above-mentioned studies performed measurements of total OC. Animal studies, however, provide evidence that it is rather ucOC hormonal functions and thus effects on glucose metabolism are attributed to. In studies measuring ucOC, it was regarded responsible for enhanced $\beta$-cell function (62) and associated with plasma glucose levels in men with T2DM (63). However, ucOC levels in patients with T1DM did not differ from those in healthy adults. ucOC levels were higher in younger subjects and correlated positively with IGF1 (64). In healthy children, higher ucOC levels were associated with higher insulin secretion (65) as well as with higher high-molecular weight adiponectin, while children with prediabetes had lower ucOC concentrations and $\beta$-cell dysfunction (66). Acute insulin response to glucose challenge correlated negatively with ucOC in middle-school children (52). Serum ucOC levels were identified as being significantly lower in patients receiving antiresorptive bone medication, reflecting suppressed bone turnover in these individuals $(67,68)$, as well as in patients on glucocorticoid therapy (68). It remains to be clarified whether osteoporotic patients on bisphosphonates might be at an increased risk of developing disturbances of glucose metabolism as a consequence of their diminished levels of ucOC (69). However, a study by Shea et al. (70) failed to show a significant link with parameters of glucose metabolism and ucOC; a connection of total or $\mathrm{COC}$ with insulin resistance could be identified, though. The reasons for these conflicting results might be species differences or imprecision of HOMA-IR as a parameter of insulin resistance, as noted by the authors (70), or methodical problems such as inhomogeneity or lack of specificity of commercially available assays, as supposed by Ducy (69).

A study by Basu et al. (71) was likewise unable to show alterations of ucOC levels upon acute changes in insulin levels, conducted in 14 patients who underwent a 7-h stepped insulin infusion accompanied by glucose clamp and somatostatin infusion. Conflicting data were revealed in a recently published study, where vitamin K2 supplementation was found to increase insulin sensitivity in healthy young men. Interestingly, this effect was ascribed to an elevation of serum cOC levels (72).

The first direct evidence in humans showing that $\mathrm{OC}$ regulates energy metabolism might be provided by Confavreux et al. (73). Two patients undergoing surgical resection of an OC-producing osteoid osteoma are described. One day after surgery, ucOC levels had decreased and serum glucose levels had strongly increased (69).

Upon perception of all these new findings regarding the role of UcOC and OC, it should be noted that $\mathrm{OC}$ is most likely not only a marker of bone turnover, and variations in its serum level might not always be the consequence of an effect on bone formation but should also possibly be regarded as a transient metabolic adaptation (69). 
These studies are cross-sectional studies that can demonstrate associations but not causality except for the osteoid osteoma cases (73). Even if some human studies remain negative, there is a growing body of evidence in humans showing that ucOC improves glucose metabolism as it does in rodents.

\section{OC and fertility: clinical evidence}

In addition to the mouse models described, this newly discovered bone-testis axis has recently been clinically supported for the first time. Kirmani et al. (74) found a significant correlation of total OC, but not P1NP, with testosterone in boys aged 11-14 years, while testosterone was significantly correlated with periosteal circumference. A trend was observed for ucOC. These results underline the importance of the bone-testis axis especially during rapid skeletal growth. Starting at a bone age of 11 years, testosterone levels rise due to hypothalamic-pituitary influences and OC increases due to skeletal growth and peaks at bone age 14 years. OC in turn stimulated testosterone production and testosterone again contributed to bone growth.

\section{OC as a treatment: preclinical treatment experiments}

Interventional studies clarifying the effects of OC on energy metabolism are still lacking as OC cannot be administered to humans. Treating mice fed a normal diet with recombinant ucOC reduced serum glucose levels and enhanced insulin secretion $(27,75)$. In mice fed a high-fat diet, glucose tolerance and insulin resistance were in part reconstituted and hepatic steatosis regressed by the injection of ucOC (75).

In humans, an intervention-like situation was achieved in a study by Schafer et al., where patients were treated with either PTH or alendronate. PTH increased whereas alendronate decreased ucOC levels. Metabolic changes were observed as higher decreases in body weight and fat mass and higher levels of adiponectin and have been attributed to increases in ucOC levels (59).

\section{A further-reaching endocrine role}

A very recent study by Yoshikawa $e$ t al. was able to show that only a part of the phenotype caused by osteoblast ablation in mice could be corrected by administration of uncarboxylated OC. Glucose intolerance was fully reversed and glucose as well as insulin levels returned to normal, but insulin sensitivity, improved gonadal fat weight, and energy expenditure were only partly restored. This suggests that osteoblasts influence energy metabolism only in part via OC and that the rest is most likely regulated in an OC-independent manner, perhaps via other osteoblast-produced hormones (76) that have not yet been identified.

\section{Conclusion}

The hypothesis of a connection between skeleton, energy metabolism, and reproduction could be supported in recent years both by experiments in mouse models and by clinical studies through the role of OC. It has been shown that not only the body acts on the bone but also that vice versa the bone influences many tissues in the human body - adipose tissue, muscle, liver, testis, pancreas, and perhaps even more. What its exact functions are, how they are exerted, and what fraction of OC (total, undercarboxylated, uncarboxylated, and carboxylated) is mostly responsible for them remain to be clarified. Is OC a long-term protector against metabolic disturbances? Is there a short-term reaction toward rises in glucose or insulin levels? Many questions remain to be answered.

In spite of yet ongoing controversial discussions concerning many of the newly proposed hypotheses and newly discovered aspects, the role of bone as an endocrine organ for the entire organism is a paradigm shift that will evoke many more medical findings.

\section{Review criteria}

PubMed was searched for articles using the terms 'OC', 'ucOC', 'leptin', 'adiponectin', and 'amylin'. Further references were derived through the reference sections of the articles found through PubMed. We apologize to colleagues whose work could not be considered and included in our review owing to space limitations.

\section{Declaration of interest}

The authors declare that there is no conflict of interest that could be perceived as prejudicing the impartiality of the research reported.

\section{Funding}

This work was supported by BioPersMed (COMET K-project 825329), which is funded by the Federal Ministry of Transport, Innovation and Technology (BMVIT) and the Federal Ministry of Economics and Labour/the Federal Ministry of Economy, Family and Youth (BMWA/BMWFJ) and the Styrian Business Promotion Agency (SFG).

\section{References}

1 Ducy P, Amling M, Takeda S, Priemel M, Schilling AF, Beil FT, Shen J, Vinson C, Rueger JM \& Karsenty G. Leptin inhibits bone formation through a hypothalamic relay: a central control of bone mass. Cell 2000100 197-207. (doi:10.1016/S0092$8674(00) 81558-5)$ 
2 Karsenty G. Convergence between bone and energy homeostases: leptin regulation of bone mass. Cell Metabolism 20064 341-348. (doi:10.1016/j.cmet.2006.10.008)

3 Confavreux $\mathrm{CB}$. Bone: from a reservoir of minerals to a regulator of energy metabolism. Kidney International. Supplement $2011 \mathbf{1 2 1}$ S14-S19. (doi:10.1038/ki.2011.25)

4 Shi Y, Yadav VK, Suda N, Liu XS, Guo XE, Myers MG Jr \& Karsenty G. Dissociation of the neuronal regulation of bone mass and energy metabolism by leptin in vivo. PNAS $2008 \mathbf{1 0 5}$ 20529-20533. (doi:10.1073/pnas.0808701106)

5 Bjornholm M, Munzberg H, Leshan RL, Villanueva EC, Bates SH, Louis GW, Jones JC, Ishida-Takahashi R, Bjorbaek C \& Myers MG Jr. Mice lacking inhibitory leptin receptor signals are lean with normal endocrine function. Journal of Clinical Investigation 2007 117 1354-1360. (doi:10.1172/JCI30688)

6 Karsenty G \& Oury F. The central regulation of bone mass, the first link between bone remodeling and energy metabolism. Journal of Clinical Endocrinology and Metabolism $2010 \quad 95$ 4795-4801. (doi:10.1210/jc.2010-1030)

7 Cornish J, Callon KE, Bava U, Lin C, Naot D, Hill BL, Grey AB, Broom N, Myers DE, Nicholson GC \& Reid IR. Leptin directly regulates bone cell function in vitro and reduces bone fragility in vivo. Journal of Endocrinology $2002 \mathbf{1 7 5} 405-415$. (doi:10.1677/joe.0.1750405)

8 Holloway WR, Collier FM, Aitken CJ, Myers DE, Hodge JM, Malakellis M, Gough TJ, Collier GR \& Nicholson GC. Leptin inhibits osteoclast generation. Journal of Bone and Mineral Research 2002 17 200-209. (doi:10.1359/jbmr.2002.17.2.200)

9 Bartell SM, Rayalam S, Ambati S, Gaddam DR, Hartzell DL, Hamrick M, She JX, Della-Fera MA \& Baile CA. Central (ICV) leptin injection increases bone formation, bone mineral density, muscle mass, serum IGF-1, and the expression of osteogenic genes in leptin-deficient ob/ob mice. Journal of Bone and Mineral Research 201126 1710-1720. (doi:10.1002/jbmr.406)

10 Williams GA, Callon KE, Watson M, Costa JL, Ding Y, Dickinson M, Wang Y, Naot D, Reid IR \& Cornish J. Skeletal phenotype of the leptin receptor-deficient $\mathrm{db} / \mathrm{db}$ mouse. Journal of Bone and Mineral Research 201126 1698-1709. (doi:10.1002/jbmr.367)

11 Richards JB, Papaioannou A, Adachi JD, Joseph L, Whitson HE, Prior JC \& Goltzman D \& Canadian Multicentre Osteoporosis Study Research Group. Effect of selective serotonin reuptake inhibitors on the risk of fracture. Archives of Internal Medicine $2007 \mathbf{1 6 7}$ 188-194. (doi:10.1001/archinte.167.2.188)

$12 \mathrm{Wu}$ Q, Bencaz AF, Hentz JG \& Crowell MD. Selective serotonin reuptake inhibitor treatment and risk of fractures: a meta-analysis of cohort and case-control studies. Osteoporosis International 2012 23 365-375. (doi:10.1007/s00198-011-1778-8)

13 Yadav VK, Oury F, Suda N, Liu ZW, Gao XB, Confavreux C, Klemenhagen KC, Tanaka KF, Gingrich JA, Guo XE, Tecott LH, Mann JJ, Hen R, Horvath TL \& Karsenty G. A serotonin-dependent mechanism explains the leptin regulation of bone mass, appetite, and energy expenditure. Cell 2009138 976-989. (doi:10.1016/ j.cell.2009.06.051)

14 Oury F \& Karsenty G. Towards a serotonin-dependent leptin roadmap in the brain. Trends in Endocrinology and Metabolism 2011 22 382-387. (doi:10.1016/j.tem.2011.04.006)

15 Takeda S, Elefteriou F, Levasseur R, Liu X, Zhao L, Parker KL, Armstrong D, Ducy P \& Karsenty G. Leptin regulates bone formation via the sympathetic nervous system. Cell $2002 \mathbf{1 1 1}$ 305-317. (doi:10.1016/S0092-8674(02)01049-8)

16 Elias CF, Lee C, Kelly J, Aschkenasi C, Ahima RS, Couceyro PR, Kuhar MJ, Saper CB \& Elmquist JK. Leptin activates hypothalamic CART neurons projecting to the spinal cord. Neuron $1998 \mathbf{2 1}$ 1375-1385. (doi:10.1016/S0896-6273(00)80656-X)

17 Kristensen P, Judge ME, Thim L, Ribel U, Christjansen KN, Wulff BS, Clausen JT, Jensen PB, Madsen OD, Vrang N, Larsen PJ \& Hastrup S. Hypothalamic CART is a new anorectic peptide regulated by leptin. Nature 1998393 72-76. (doi:10.1038/ 29993)

18 Elefteriou F, Ahn JD, Takeda S, Starbuck M, Yang X, Liu X, Kondo H, Richards WG, Bannon TW, Noda M, Clement K, Vaisse C
\& Karsenty G. Leptin regulation of bone resorption by the sympathetic nervous system and CART. Nature $2005 \mathbf{4 3 4}$ 514-520. (doi:10.1038/nature03398)

19 Singh MK, Elefteriou F \& Karsenty G. Cocaine and amphetamineregulated transcript may regulate bone remodeling as a circulating molecule. Endocrinology $2008 \quad 149$ 3933-3941. (doi:10.1210/en.2008-0109)

20 Brown JP, Delmas PD, Malaval L, Edouard C, Chapuy MC \& Meunier PJ. Serum bone Gla-protein: a specific marker for bone formation in postmenopausal osteoporosis. Lancet 19841 1091-1093. (doi:10.1016/S0140-6736(84)92506-6)

21 Delmas PD, Stenner D, Wahner HW, Mann KG \& Riggs BL. Increase in serum bone $\gamma$-carboxyglutamic acid protein with aging in women. Implications for the mechanism of age-related bone loss. Journal of Clinical Investigation 198371 1316-1321. (doi:10.1172/JCI110882)

22 Bugel S. Vitamin K and bone health in adult humans. Vitamins and Hormones $2008 \mathbf{7 8}$ 393-416.

23 Hauschka PV, Lian JB, Cole DE \& Gundberg CM. Osteocalcin and matrix Gla protein: vitamin K-dependent proteins in bone. Physiological Reviews 198969 990-1047.

24 Booth SL, Lichtenstein AH, O’Brien-Morse M, McKeown NM, Wood RJ, Saltzman E \& Gundberg CM. Effects of a hydrogenated form of vitamin $\mathrm{K}$ on bone formation and resorption. American Journal of Clinical Nutrition 2001 74 783-790.

25 Lee NK, Sowa H, Hinoi E, Ferron M, Ahn JD, Confavreux C, Dacquin R, Mee PJ, McKee MD, Jung DY, Zhang Z, Kim JK, Mauvais-Jarvis F, Ducy P \& Karsenty G. Endocrine regulation of energy metabolism by the skeleton. Cell $2007 \mathbf{1 3 0} 456-469$. (doi:10.1016/j.cell.2007.05.047)

26 Hinoi E, Gao N, Jung DY, Yadav V, Yoshizawa T, Myers MG Jr, Chua SC Jr, Kim JK, Kaestner KH \& Karsenty G. The sympathetic tone mediates leptin's inhibition of insulin secretion by modulating osteocalcin bioactivity. Journal of Cell Biology 2008 183 1235-1242. (doi:10.1083/jcb.200809113)

27 Ferron M, Hinoi E, Karsenty G \& Ducy P. Osteocalcin differentially regulates $\beta$ cell and adipocyte gene expression and affects the development of metabolic diseases in wild-type mice. PNAS 2008 105 5266-5270. (doi:10.1073/pnas.0711119105)

28 Covey SD, Wideman RD, McDonald C, Unniappan S, Huynh F, Asadi A, Speck M, Webber T, Chua SC \& Kieffer TJ. The pancreatic $\beta$ cell is a key site for mediating the effects of leptin on glucose homeostasis. Cell Metabolism 20064 291-302. (doi:10.1016/ j.cmet.2006.09.005)

29 Morioka T, Asilmaz E, Hu J, Dishinger JF, Kurpad AJ, Elias CF, Li H, Elmquist JK, Kennedy RT \& Kulkarni RN. Disruption of leptin receptor expression in the pancreas directly affects $\beta$ cell growth and function in mice. Journal of Clinical Investigation 2007117 2860-2868. (doi:10.1172/JCI30910)

30 Ferron M, Wei J, Yoshizawa T, Del Fattore A, DePinho RA, Teti A, Ducy P \& Karsenty G. Insulin signaling in osteoblasts integrates bone remodeling and energy metabolism. Cell 2010142 296-308. (doi:10.1016/j.cell.2010.06.003)

31 Kanazawa I, Yamaguchi T, Yano S, Yamauchi M, Yamamoto M \& Sugimoto T. Adiponectin AMP kinase activator stimulate proliferation, differentiation, and mineralization of osteoblastic MC3T3-E1 cells. BMC Cell Biology 20078 51. (doi:10.1186/ 1471-2121-8-51)

32 Oury F, Sumara G, Sumara O, Ferron M, Chang H, Smith CE, Hermo L, Suarez S, Roth BL, Ducy P \& Karsenty G. Endocrine regulation of male fertility by the skeleton. Cell $2011 \mathbf{1 4 4}$ 796-809. (doi:10.1016/j.cell.2011.02.004)

$33 \mathrm{Pi} \mathrm{M}$, Faber P, Ekema G, Jackson PD, Ting A, Wang N, Fontilla-Poole M, Mays RW, Brunden KR, Harrington JJ \& Quarles LD. Identification of a novel extracellular cation-sensing G-protein-coupled receptor. Journal of Biological Chemistry 2005 280 40201-40209. (doi:10.1074/jbc.M505186200)

34 Foresta C, Strapazzon G, De Toni L, Gianesello L, Calcagno A, Pilon C, Plebani M \& Vettor R. Evidence for osteocalcin production 
by adipose tissue and its role in human metabolism. Journal of Clinical Endocrinology and Metabolism 201095 3502-3506. (doi:10.1210/jc.2009-2557)

35 Gapstur SM, Gann PH, Kopp P, Colangelo L, Longcope C \& Liu K. Serum androgen concentrations in young men: a longitudinal analysis of associations with age, obesity, and race. The CARDIA male hormone study. Cancer Epidemiology, Biomarkers \& Prevention 200211 1041-1047.

36 Pasquali R, Casimirri F, Cantobelli S, Melchionda N, Morselli Labate AM, Fabbri R, Capelli M \& Bortoluzzi L. Effect of obesity and body fat distribution on sex hormones and insulin in men. Metabolism: Clinical and Experimental 199140 101-104. (doi:10. 1016/0026-0495(91)90199-7)

37 Seidell JC, Bjorntorp P, Sjostrom L, Kvist H \& Sannerstedt R. Visceral fat accumulation in men is positively associated with insulin, glucose, and C-peptide levels, but negatively with testosterone levels. Metabolism: Clinical and Experimental 1990 39 897-901. (doi:10.1016/0026-0495(90)90297-P)

38 Tsai EC, Matsumoto AM, Fujimoto WY \& Boyko EJ. Association of bioavailable, free, and total testosterone with insulin resistance: influence of sex hormone-binding globulin and body fat. Diabetes Care 200427 861-868. (doi:10.2337/diacare.27.4.861)

39 Rosato MT, Schneider SH \& Shapses SA. Bone turnover and insulin-like growth factor I levels increase after improved glycemic control in noninsulin-dependent diabetes mellitus. Calcified Tissue International 199863 107-111. (doi:10.1007/ s002239900498)

40 Kindblom JM, Ohlsson C, Ljunggren O, Karlsson MK, Tivesten A, Smith U \& Mellstrom D. Plasma osteocalcin is inversely related to fat mass and plasma glucose in elderly Swedish men. Journal of Bone and Mineral Research 200924 785-791. (doi:10.1359/jbmr. 081234)

41 Pittas AG, Harris SS, Eliades M, Stark P \& Dawson-Hughes B. Association between serum osteocalcin and markers of metabolic phenotype. Journal of Clinical Endocrinology and Metabolism 2009 94 827-832. (doi:10.1210/jc.2008-1422)

42 Fernandez-Real JM, Izquierdo M, Ortega F, Gorostiaga E, Gomez-Ambrosi J, Moreno-Navarrete JM, Fruhbeck G, Martinez C, Idoate F, Salvador J, Forga L, Ricart W \& Ibanez J. The relationship of serum osteocalcin concentration to insulin secretion, sensitivity, and disposal with hypocaloric diet and resistance training. Journal of Clinical Endocrinology and Metabolism 200994 237-245. (doi:10.1210/jc.2008-0270)

43 Im JA, Yu BP, Jeon JY \& Kim SH. Relationship between osteocalcin and glucose metabolism in postmenopausal women. Clinica Chimica Acta 2008396 66-69. (doi:10.1016/j.cca.2008.07.001)

44 Paldanius PM, Ivaska KK, Hovi P, Andersson S, Vaananen HK, Kajantie E \& Makitie O. The effect of oral glucose tolerance test on serum osteocalcin and bone turnover markers in young adults. Calcified Tissue International 201190 90-95. (doi:10.1007/ s00223-011-9551-8)

45 Levinger I, Zebaze R, Jerums G, Hare DL, Selig S \& Seeman E. The effect of acute exercise on undercarboxylated osteocalcin in obese men. Osteoporosis International 201122 1621-1626. (doi:10.1007/s00198-010-1370-7)

46 Grimston SK, Tanguay KE, Gundberg CM \& Hanley DA. The calciotropic hormone response to changes in serum calcium during exercise in female long distance runners. Journal of Clinical Endocrinology and Metabolism 199376 867-872. (doi:10.1210/ jc.76.4.867)

47 Rong H, Berg U, Torring O, Sundberg CJ, Granberg B \& Bucht E. Effect of acute endurance and strength exercise on circulating calcium-regulating hormones and bone markers in young healthy males. Scandinavian Journal of Medicine \& Science in Sports 19977 152-159. (doi:10.1111/j.1600-0838.1997.tb00132.x)

48 Tosun A, Bolukbasi N, Cingi E, Beyazova M \& Unlu M. Acute effects of a single session of aerobic exercise with or without weight-lifting on bone turnover in healthy young women. Modern Rheumatology/ the Japan Rheumatism Association 200616 300-304.
49 Welsh L, Rutherford OM, James I, Crowley C, Comer M \& Wolman R. The acute effects of exercise on bone turnover. International Journal of Sports Medicine $1997 \quad 18$ 247-251. (doi:10.1055/s-2007-972628)

50 Reinehr T \& Roth CL. A new link between skeleton, obesity and insulin resistance: relationships between osteocalcin, leptin and insulin resistance in obese children before and after weight loss. International Journal of Obesity 201034 852-858. (doi:10.1038/ ijo.2009.282)

51 Granado-Lorencio F, Simal-Anton A, Salazar-Mosteiro J, HerreroBarbudo C, Donoso-Navarro E, Blanco-Navarro I \& PerezSacristan B. Time-course changes in bone turnover markers and fat-soluble vitamins after obesity surgery. Obesity Surgery 201020 1524-1529. (doi:10.1007/s11695-010-0257-1)

52 Boucher-Berry C, Speiser PW, Carey DE, Shelov SP, Accacha S, Fennoy I, Rapaport R, Espinal Y \& Rosenbaum M. Vitamin D osteocalcin and risk for adiposity as co-morbidities in middle school children. Journal of Bone and Mineral Research 2012 In press. (doi: 10.1002/jbmr.55)

53 Winhofer Y, Handisurya A, Tura A, Bittighofer C, Klein K, Schneider B, Bieglmayer C, Wagner OF, Pacini G, Luger A \& Kautzky-Willer A. Osteocalcin is related to enhanced insulin secretion in gestational diabetes mellitus. Diabetes Care 201033 139-143. (doi:10.2337/dc09-1237)

54 Kanazawa I, Yamaguchi T, Yamauchi M, Yamamoto M, Kurioka S, Yano S \& Sugimoto T. Adiponectin is associated with changes in bone markers during glycemic control in type 2 diabetes mellitus. Journal of Clinical Endocrinology and Metabolism 200994 3031-3037. (doi:10.1210/jc.2008-2187)

55 Kanazawa I, Yamaguchi T, Yamamoto M, Yamauchi M, Kurioka S, Yano S \& Sugimoto T. Serum osteocalcin level is associated with glucose metabolism and atherosclerosis parameters in type 2 diabetes mellitus. Journal of Clinical Endocrinology and Metabolism 200994 45-49. (doi:10.1210/jc.2008-1455)

56 Kanazawa I, Yamaguchi T, Tada Y, Yamauchi M, Yano S \& Sugimoto T. Serum osteocalcin level is positively associated with insulin sensitivity and secretion in patients with type 2 diabetes. Bone 201148 720-725. (doi:10.1016/j.bone.2010.12.020)

57 Yeap BB, Chubb SA, Flicker L, McCaul KA, Ebeling PR, Hankey GJ, Beilby JP \& Norman PE. Associations of total osteocalcin with all-cause and cardiovascular mortality in older men. The Health In Men Study. Osteoporosis International 201123 599-606. (doi:10.1007/s00198-011-1586-1)

58 Gravenstein KS, Napora JK, Short RG, Ramachandran R, Carlson OD, Metter EJ, Ferrucci L, Egan JM \& Chia CW. Crosssectional evidence of a signaling pathway from bone homeostasis to glucose metabolism. Journal of Clinical Endocrinology and Metabolism 201196 E884-E890. (doi:10.1210/jc.2010-2589)

59 Schafer AL, Sellmeyer DE, Schwartz AV, Rosen CJ. Vittinghoff E, Palermo L, Bilezikian JP, Shoback DM \& Black DM. Change in undercarboxylated osteocalcin is associated with changes in body weight, fat mass, and adiponectin: parathyroid hormone (1-84) or alendronate therapy in postmenopausal women with osteoporosis (the PaTH Study). Journal of Clinical Endocrinology and Metabolism 201196 E1982-E1989. (doi:10.1210/jc.2011-0587)

60 Faraj M, Havel PJ. Phelis S, Blank D, Sniderman AD \& Cianflone K. Plasma acylation-stimulating protein, adiponectin, leptin, and ghrelin before and after weight loss induced by gastric bypass surgery in morbidly obese subjects. Journal of Clinical Endocrinology and Metabolism 200388 1594-1602. (doi:10.1210/jc.2002021309)

61 Yang WS, Lee WJ, Funahashi T, Tanaka S, Matsuzawa Y, Chao CL, Chen CL, Tai TY \& Chuang LM. Weight reduction increases plasma levels of an adipose-derived anti-inflammatory protein, adiponectin. Journal of Clinical Endocrinology and Metabolism $2001 \mathbf{8 6}$ 3815-3819. (doi:10.1210/jc.86.8.3815)

62 Hwang YC, Jeong IK, Ahn KJ \& Chung HY. The uncarboxylated form of osteocalcin is associated with improved glucose tolerance and enhanced $\beta$-cell function in middle-aged male subjects. Diabetes/Metabolism Research and Reviews 200925 768-772. (doi:10.1002/dmrr.1045) 
63 Kanazawa I, Yamaguchi T, Yamauchi M, Yamamoto M, Kurioka S, Yano S \& Sugimoto T. Serum undercarboxylated osteocalcin was inversely associated with plasma glucose level and fat mass in type 2 diabetes mellitus. Osteoporosis International 201122 187-194. (doi:10.1007/s00198-010-1184-7)

64 Thrailkill KM, Jo CH, Cockrell GE, Moreau CS, Lumpkin CK Jr \& Fowlkes JL. Determinants of undercarboxylated and carboxylated osteocalcin concentrations in type 1 diabetes. Osteoporosis International 2012 In press.

65 Prats-Puig A, Mas-Parareda M, Riera-Perez E, Gonzalez-Forcadell D, Mier C, Mallol-Guisset M, Diaz M, Bassols J, de Zegher F, Ibanez L \& Lopez-Bermejo A. Carboxylation of osteocalcin affects its association with metabolic parameters in healthy children. Diabetes Care 2010 33 661-663. (doi:10.2337/dc09-1837)

66 Pollock NK, Bernard PJ, Gower BA, Gundberg CM, Wenger K, Misra S, Bassali RW \& Davis CL. Lower uncarboxylated osteocalcin concentrations in children with prediabetes is associated with $\beta$-cell function. Journal of Clinical Endocrinology and Metabolism 201196 E1092-E1099. (doi:10.1210/jc.2010-2731)

67 Aonuma H, Miyakoshi N, Hongo M, Kasukawa Y \& Shimada Y. Low serum levels of undercarboxylated osteocalcin in postmenopausal osteoporotic women receiving an inhibitor of bone resorption. Tohoku Journal of Experimental Medicine 2009218 201-205. (doi:10.1620/tjem.218.201)

68 Mokuda S, Okuda Y, Onishi M, Sawada N, Matoba K, Yamada A Jouyama K \& Takasugi K. Postmenopausal women with rheumatoid arthritis who are treated with raloxifene or alendronate or glucocorticoids have lower serum undercarboxylated osteocalcin (ucOC) levels. Journal of Endocrinological Investigation 2012 In press.

69 Ducy P. The role of osteocalcin in the endocrine cross-talk between bone remodelling and energy metabolism. Diabetologia 201154 1291-1297. (doi:10.1007/s00125-011-2155-z)

70 Shea MK, Gundberg CM, Meigs JB, Dallal GE, Saltzman E, Yoshida M, Jacques PF \& Booth SL. $\gamma$-Carboxylation of osteocalcin and insulin resistance in older men and women. American Journal of Clinical Nutrition 200990 1230-1235. (doi:10.3945/ ajcn.2009.28151)

71 Basu R, Peterson J, Rizza R \& Khosla S. Effects of physiological variations in circulating insulin levels on bone turnover in humans. Journal of Clinical Endocrinology and Metabolism 2011 96 1450-1455. (doi:10.1210/jc.2010-2877)

72 Choi HJ, Yu J, Choi H, An JH, Kim SW, Park KS, Jang HC, Kim SY \& Shin CS. Vitamin K2 supplementation improves insulin sensitivity via osteocalcin metabolism: a placebo-controlled trial. Diabetes Care 201134 e147. (doi:10.2337/dc11-0551)

73 Confavreux CB, Borel O, Lee F, Vaz G, Guyard M, Fadat C, Carlier MC, Chapurlat R \& Karsenty G. Osteoid osteoma is an osteocalcinoma affecting glucose metabolism. Osteoporosis International 2012 In press.

74 Kirmani S, Atkinson EJ, Melton LJ III, Riggs BL, Amin S \& Khosla S. Relationship of testosterone and osteocalcin levels during growth. Journal of Bone and Mineral Research $2011262212-2216$. (doi:10.1002/jbmr.421)

75 Ferron M, McKee MD, Levine RL, Ducy P \& Karsenty G. Intermittent injections of osteocalcin improve glucose metabolism and prevent type 2 diabetes in mice. Bone 201150 568-575. (doi:10.1016/j.bone.2011.04.017)

76 Yoshikawa Y, Kode A, Xu L, Mosialou I, Silva BC, Ferron M, Clemens TL, Economides AN \& Kousteni S. Genetic evidence points to an osteocalcin-independent influence of osteoblasts on energy metabolism. Journal of Bone and Mineral Research 201126 2012-2025. (doi:10.1002/jbmr.417)

Received 21 November 2011

Revised version received 8 March 2012

Accepted 21 March 2012 